\title{
O conhecimento sobre a população atendida no estágio em Serviço Social
}

\author{
Knowledge regarding the population served by Social Work interns \\ Simone Sobral SAMPAIO* \\ https://orcid.org/o00o-0003-3452-5414 \\ Robson de OLIVEIRA** \\ https://orcid.org/o00o-0003-3271-4086
}

\begin{abstract}
Resumo: Este artigo apresenta o Estágio Supervisionado em Serviço Social como um importante meio de aprendizado da dinâmica do exercício profissional. No âmbito da investigação, destaca-se a existência de uma lacuna nas discussões sobre o tema, qual seja, o conhecimento da população que busca o atendimento do Serviço Social. O texto apresenta as Diretrizes Curriculares, o objetivo da formação profissional e o conjunto de possibilidades ofertadas pelo conhecimento da população atendida pelo/a Assistente Social. E conclui que conhecer a população atendida é um elemento estratégico na assunção política da direção social da profissão, especialmente na definição de estratégias que possibilitem a construção de uma relação contrária à institucionalização, a qual reforça vínculos de subalternidade no exercício profissional dos/as assistentes sociais.
\end{abstract}

Palavras-chave: Estágio Supervisionado. Exercício profissional. População atendida.

Abstract: This article presents Supervised Internships in Social Work as an important means for learning the dynamics of professional practice. Within the scope of the research, this article highlights a gap in discussions around the topic, namely, knowledge regarding the population that seeks out Social Service assistance. The text presents the Curricular Guidelines, vocational training objectives, and the possibilities offered by knowledge of the population served by Social Workers. It concludes that knowing the served population is a strategic element in designing policy that then determines the social direction of the profession, especially with regards to defining strategies that enable the establishment of a relationship contrary to institutionalization and which reinforces bonds in social workers' professional practice.

Keywords: Supervised Internship. Professional Practice. Served Population.

Submetido em: 14/11/2019. Revisado em: 26/7/2020; 4/8/2020. Aceito em: 17/9/2020.

\footnotetext{
* Assistente Social. Doutora em Serviço Social. Professora do curso de Serviço Social da Universidade Federal de Santa Catarina. (UFSC, Florianópolis, Brasil). R. Eng. Agronômico Andrei Cristian Ferreira, s/n - Trindade, 88040-90o. E-mail: simonessamp@gmail.com.

${ }^{* *}$ Assistente Social. Doutor em Serviço Social. Professor do curso de Serviço Social da Universidade Federal do Paraná - Setor Litoral. (UFPr, Matinhos, Brasil). Rua Jaguariaíva, Tv. Caiobá, 512, 83260ooo. E-mail: robson.de.oliveira@ufpr.br.
} copiar e redistribuir o material em qualquer suporte ou formato, bem como adaptar, transformar e criar a partir deste material para qualquer fim, mesmo que comercial. O licenciante não pode revogar estes direitos desde que você respeite os termos da licença. 


\section{Introdução}

profissão de Assistente Social no Brasil possui possui uma direção social
apoiada em uma formação que articula fundamentos ético-políticos, teórico1 metodológicos e técnico-operativos organizados, analiticamente, no entendimento crítico da formação histórica brasileira, no conhecimento basilar do funcionamento da sociedade capitalista, na gênese dos direitos nos processos de luta e resistência da classe trabalhadora, nos requisitos e competências profissionais. $\mathrm{O}$ Estágio não é uma peça descolada dessa formação, pelo contrário, ele está entranhado na complexidade da vida social enquanto realidade que sinaliza as condições de trabalho, as requisições institucionais e, fundamentalmente, as demandas dos usurários das políticas sociais (ASSOCIAÇÃO BRASILEIRA DE ENSINO EM SERVIÇO SOCIAL; CENTRO DE DOCUMENTAÇÃO E PESQUISA EM POLÍTICAS SOCIAIS E SERVIÇO SOCIAL, 1996b).

Nesse sentido, pode-se afirmar que o Estágio à formação profissional possui expressiva importância, o que não significa blindar ou afastar o debate necessário, tampouco entronizá-lo como elemento principal da formação, seja qual for o curso de graduação do qual ele faça parte. Diante do reconhecimento da importância do Estágio na formação profissional do/a Assistente Social, é preciso atentar para um aspecto central, qual seja, a necessidade de se conhecer os sujeitos demandantes/atendidos. É a partir desse aspecto que este texto objetiva discorrer sobre a problematização do Estágio na graduação em Serviço Social, especialmente no que se refere ao conhecimento da população atendida pelas políticas sociais, serviços e espaços sócio-ocupacionais.

Entender a questão social, sua particularidade na relação com a política social, os movimentos sociais constituintes dessa história, a forma como ela se desdobra no espaço sócio-ocupacional, bem como as requisições à elaboração de estratégias profissionais por parte do/a Assistente Social, viabilizam as mediações necessárias a serem ofertadas pelo Estágio ao processo de formação profissional.

Muitas vezes, porém, depara-se, no âmbito das supervisões acadêmica e profissional, com uma grande dificuldade dos/das estudantes de definirem a particularidade da questão social que cabe ao exercício profissional em determinado espaço socioocupacional, ou seja, o próprio objeto profissional sofre um processo de obnubilação. Esse processo afeta o conhecimento que o discente apreende no campo de estágio. A dificuldade do/a Assistente Social definir seu objeto profissional traz a rebote outras dificuldades, que inclui desde aspectos mais formais relacionados a instituição - afinal qual seria a função do Serviço Social em determinado espaço socio-ocupacional - até mesmo a incapacidade de distinguir em seu exercício profissional o que faz o/a Assistente Social diante da inserção em que se encontra. Somado a essas questões há outro elemento caro a esse processo que, também, precisa ser enfrentado pela categoria profissional: a dificuldade em conhecer, de forma adequada, a quem os serviços sociais se destinam, as formas de organização popular, as estratégias de sobrevivência da população usuária dos serviços e políticas sociais, em suma, os segmentos da classe trabalhadora a quem se destinam a ação profissional.

Argum., Vitória, v. 12, n. 3, p. 296-307, set./dez. 2020. | ISSN 2176-9575 


\section{Estágio e população atendida: reflexões necessárias}

Uma detida observação nas publicações oficiais da categoria profissional sobre Estágio em Serviço Social - a exemplo da Lei de Regulamentação da Profissão (Lei n. 8.662/2003), o Código de Ética do/a Assistente Social e a Resolução CFESS n. 533/2008, que regulamenta a Supervisão Direta de Estágio no Serviço Social (CFESS, 2011abc) serve para sinalizar os esforços, principalmente no que se refere às supervisões acadêmica e profissional na busca por uma compreensão mais rica das mediações que as envolvem. Sobre isso é revelador o lugar que o Estágio ocupa na formação em Serviço Social. De acordo com as Diretrizes Gerais para o Curso de Serviço Social (ASSOCIAÇÃO BRASILEIRA DE ENSINO EM SERVIÇO SOCIAL; CENTRO DE DOCUMENTAÇÃO E PESQUISA EM POLÍTICAS SOCIAIS E SERVIÇO SOCIAL, 1996a), o Projeto Pedagógico do curso deve explicitar o formato do Estágio Supervisionado; a integração do ensino das disciplinas com o Estágio, dentre outros componentes curriculares; a indissociabilidade entre a supervisão acadêmica e profissional na atividade de Estágio; o Estágio Supervisionado e a sua pertença ao núcleo de fundamentos do trabalho profissional. Tais diretrizes assim definem o Estágio Supervisionado:

[...] uma atividade curricular obrigatória que se configura a partir da inserção do aluno no espaço socioinstitucional, objetivando capacitá-lo para o exercício profissional, o que pressupõe supervisão sistemática. Esta supervisão será feita conjuntamente por professor supervisor e por profissional do campo, com base em planos de estágio elaborados em conjunto pelas unidades de ensino e organizações que oferecem estágio (ASSOCIAÇÃO BRASILEIRA DE ENSINO EM SERVIÇO SOCIAL; CENTRO DE DOCUMENTAÇÃO E PESQUISA EM POLÍTICAS SOCIAIS E SERVIÇO SOCIAL, 1996a, p. 71).

A proposta encaminhada pela categoria profissional e o documento aprovado pelo Conselho Nacional de Educação sofreram alterações (IAMAMOTO, 2012; ABREU, 2007), contudo, os aspectos restritos ao Estágio Supervisionado não tiveram nenhuma mudança se comparados à proposta de Diretrizes Curriculares da ABEPSS/CEDEPSS (1996a), às Diretrizes Curriculares elaboradas pela equipe de especialistas em 1999, tampouco às Diretrizes Curriculares para o curso de Serviço Social aprovada pelo MEC/CNE em 2002 (BRASIL, 2002). Sua definição se manteve, o que significa que o seu lugar no núcleo de fundamentos do trabalho profissional não foi alterado. Durante o Estágio Supervisionado cabe ao estudante aprender a forma como o/a Assistente Social constrói as suas estratégias profissionais a partir de instrumental técnicooperativo que, ao se realizar, nunca são um fim em si mesmo.

Nos documentos supracitados (CONSELHO FEDERAL DE SERVIÇO SOCIAL, 2011a; CONSELHO FEDERAL DE SERVIÇO SOCIAL, 2011b; CONSELHO FEDERAL DE SERVIÇO SOCIAL, 2011C; BRASIL, 2002; ASSOCIAÇÃO BRASILEIRA DE ENSINO EM SERVIÇO SOCIAL; CENTRO DE DOCUMENTAÇÃO E PESQUISA EM POLÍTICAS SOCIAIS E SERVIÇO SOCIAL, 1996a). constata-se que a preocupação é unânime em entender, no campo da formação profissional, a função que cabe aos supervisores (acadêmico e profissional). Destarte, a supervisão é entendida como constituinte do processo de ensino-aprendizagem a partir dos processos de trabalho profissional em distintos espaços ocupacionais, no caso, o campo de Estágio (IAMAMOTO, 2003). Esta

Argum., Vitória, v. 12, n. 3, p. 296-307, set./dez. 2020. | ISSN 2176-9575 
é uma tarefa decisiva e estratégica que assegura à formação a riqueza da experiência na atuação profissional.

Dessa maneira, cabe tensionar, a partir de certos elementos constituintes do Estágio em Serviço Social, a sua relação direta com a formação profissional e o exercício profissional. Nos documentos apresentados e formulados pela categoria profissional sobre o Estágio há uma atenção e cuidado no que se refere à inserção sócioocupacional desde elementos normativos - tais como carga horária, quantitativo de supervisionados por profissional, obrigatoriedade da apresentação de um plano de trabalho do Serviço Social no campo de estágio - até a sua natureza imprescíndivel à formação profissional (CONSELHO FEDERAL DE SERVIÇO SOCIAL, 2011a; CONSELHO FEDERAL DE SERVIÇO SOCIAL, 2011b; CONSELHO FEDERAL DE SERVIÇO SOCIAL, 2011c; ASSOCIAÇÃO BRASILEIRA DE ENSINO EM SERVIÇO SOCIAL; CENTRO DE DOCUMENTAÇÃO E PESQUISA EM POLÍTICAS SOCIAIS E SERVIÇO SOCIAL, 1996a).

Tudo isso está bem fundamentado e justificado na processualidade do reconhecimento concedido ao Estágio no processo de formação. Somado a isso - conforme previsto na Resolução n. 533/2008, que regulamenta a Supervisão Direta de Estágio no Serviço Social (CONSELHO FEDERAL DE SERVIÇO SOCIAL, 2011c) - há, ainda, o necessário cuidado acerca da fiscalização desse momento da formação a fim de assegurar que o Estágio não seja uma forma de adensar a superexploração do trabalho por meio do uso de uma força de trabalho não qualificada e mais barata. Esta é uma preocupação constante na relação das instituições de formação junto aos Conselhos Regionais de Serviço Social.

Como exemplo pode-se citar a campanha do Conjunto CFESS/CRESS: "Sou Assistente Social e Supervisiono Estágio", lançada no final de 2017, que defende a relevância político-pedagógica desse momento no processo de formação, bem como do próprio exercício profissional:

\begin{abstract}
A ABEPSS entende que a supervisão se constitui em um dos lócus estratégicos para a defesa do projeto ético-político profissional. Partimos de uma concepção de profissão que compreende a atuação profissional nas expressões da questão social, formulando, implementando e avaliando propostas para seu enfrentamento, por meio de políticas públicas, dos movimentos sociais e das organizações do terceiro setor. [...] Essa concepção de profissão necessita da articulação dinâmica e dialética entre as dimensões da formação profissional, do trabalho profissional e da organização política do coletivo profissional. E isso, em termos da supervisão de estágio, refere-se à indissociabilidade entre supervisão acadêmica e supervisão de campo (CONSELHO FEDERAL DE SERVIÇO SOCIAL; CONSELHO REGIÃO DE SERVIÇO SOCIAL, 2017).
\end{abstract}

Embora não encerrem as requisições ao processo de formação, esse cuidado por parte dos órgãos de representação da categoria, das instituições de ensino e dos espaços sócio-ocupacionais concedentes de Estágio são a base que propicia e viabiliza a sua efetivação. Ou seja, pensar o Estágio em Serviço Social a partir do processo de formação e trabalho profissional exige conhecer as questões em aberto e buscar uma articulação entre elas para que o processo congregue, a partir da supervisão - tanto 
acadêmica como de campo - estratégias profissionais desenvolvidas a partir da especificidade do espaço de trabalho, suas políticas e serviços específicos. E, por extensão, pelo conhecimento da população com quem trabalha a partir da realidade apresentada pelo próprio demandante, reconhecer a legitimidade de suas demandas. Essas estratégias são constituintes da forma como o profissional exerce a sua autonomia relativa, a fim de evitar a reprodução do meramente instituído.

Nesse sentido, um primeiro elemento a ser mencionado é a necessidade de conhecer não apenas a política social ou o serviço no qual o profissional se insere - as diretrizes, normas e orientações técnicas produzidas desde os órgãos gestores até as entidades de representação profissional - mas, também, atentar, de forma mais premente, aos usuários das políticas sociais.

De modo geral, emana da organização e do seu aparato técnico-burocrático, o conhecimento de quem são os destinatários do serviço. Desses espaços sócioocupacionais partem as caracterizações que delimitam os usuários e o seu perfil, todavia, o reconhecimento do sujeito atendido de acordo com a realidade social, a identificação das expressões da questão social materializada na reprodução de sua existência e o significado do acesso e usufruto ao serviço ou política ofertada precisam, também, ser escrutinados no âmbito do Estágio, seja pela formação e trabalho profissional ou pela bibliografia produzida pela própria categoria. Contribui, também, nesse contexto, um intenso processo de conhecimento empírico e crítico do estagiário, profissional supervisor e acadêmico.

Quando se restringe o conhecimento sobre os sujeitos a quem esses serviços e políticas se destinam, por exemplo, reduzindo-os apenas aos documentos normativos, tende-se a marginalizar o sujeito principal dos processos organizativos dos direitos sociais e o principal aliado da relação de forças que afeta, positivamente, o exercício profissional. $\mathrm{O}$ que se quer afirmar com isso é que o cadastro institucional produz uma biografia despolitizada como resultante de um formulário que tende a adequar a existência individual a informações de interesse institucional. Para ilustrar, apresenta-se o testemunho literário de Carolina Maria de Jesus (2018), para quem o Serviço Social só quer saber o nome e o endereço do sujeito.

Devido eu carregar muito ferro fiquei com dor nos rins. Para não ver os meus filhos passar fome fui pedir auxílio ao propalado Serviço Social. Foi lá que eu vi as lágrimas deslizar dos olhos dos pobres. Como é pungente ver os dramas que ali se desenrolam. A ironia com que são tratados os pobres. A única coisa que eles querem saber são os nomes e os endereços dos pobres (JESUS, 2018, p. 42).

O cadastro, enquanto instrumento de controle do itinerário da pobreza, se mostra insuficiente quando se quer conhecer a realidade dos sujeitos. Não se está propondo aqui o refinamento ainda mais vigilante desse instrumento ou uma mera qualificação dos instrumentos de decifração da pobreza. A saída para uma formação crítica e comprometida com os valores promulgados pelo Código de Ética Profissional não pode ser interpretada como incremento dos infindáveis meios de registro acerca da pobreza que reforçam, em tempos de neoliberalismo e atomização dos indivíduos, a 
culpabilização do pobre pela sua própria condição. Urge, portanto, valorizar uma relação privilegiada que o/a Assistente Social pode desenvolver com a população e com os sujeitos atendidos, podendo refletir sobre o exercício profissional no espaço da formação e do trabalho profissional.

A importância de se conhecer os sujeitos atendidos pelo/a Assistente Social é destacada na literatura do Serviço Social:

Uma hipótese de trabalho sobre o desenvolvimento do Serviço Social nos anos 1980 indica que a profissão teve os olhos mais voltados para o Estado e menos para a sociedade; mais para as políticas sociais e menos para os sujeitos com quem trabalha: o modo e condições de vida, a cultura, as condições de vida dos indivíduos sociais são pouco estudadas e conhecidas. Esse privilégio atribuído às políticas sociais foi essencial, tendo permitido uma redefinição e ampliação das bases de reconhecimento da profissão pelos empregadores e usuários dos serviços prestados. Mas, não raras vezes, redundou em uma secundarização da sociedade civil e hoje se faz urgente uma aproximação às condições de vida e de trabalho dos usuários dos seus serviços para decifrar as suas formas de organização cultural, social e política, suas experiências e interesses expressos não só no campo das organizações coletivas, político-partidárias ou sindicais, mas em suas lutas por melhorias de vida e no conjunto de suas expressões associativas e culturais que expressam modo de viver e de pensar, de enfrentar e resistir a essas desigualdades sociais. Foi afirmado que apreender a questão social é também apreender como os sujeitos a vivenciam. Ora, desvelar as condições de vida dos indivíduos, grupos e coletividades com as quais se trabalha é um dos requisitos para que se possa decifrar as diversas formas de luta, orgânicas ou não, que estão sendo gestadas e alimentadas, com inventividade, pela população. É condição ainda para se perceber as aspirações, os núcleos de contestação, a capacidade de imaginação e de invenção da sociedade aí presentes, que contêm misturados elementos de recusa e afirmação do ordenamento social vigente. Esta parece ser uma das condições para que o assistente social possa romper com a relação tutelar e de estranhamento com os sujeitos junto aos quais se trabalha e um caminho fértil para a formulação de propostas novas de trabalho. Muitas vezes, o profissional move-se pela vontade de estar junto com a população atendida, mas objetivamente não está próximo de seus interesses como coletividade, sendo, de fato, um estranho para os indivíduos com que trabalha (IAMAMOTO, 2003, p. 75-76).

Conhecer as condições de vida dos usuários implica mais do que coletar informações para o preenchimento de cadastros ou formulários, mas constitui-se como intenso processo de politização de uma relação que não pode se basear na indiferença, no estranhamento e no medo. A relação intersubjetiva movida pela ética pressupõe uma relação horizontal entre os sujeitos, assim, o primeiro passo é reconhecer que se trabalha com sujeitos munidos de carências e aspirações, histórias, aprendizados e ensinamentos, cujas necessidades não são da ordem do pontual, mas traduzem o processo de exploração e de opressão do qual sofrem. Muitas vezes, esses sujeitos não encontram nas instituições promotoras das políticas sociais qualquer reconhecimento de sua real condição, pois o estratificam a partir do que entendem que deve ser oferecido e atendido, vindo até mesmo a excluí-lo, o que reforça a cultura da subalternidade.

Argum., Vitória, v. 12, n. 3, p. 296-307, set./dez. 2020. | ISSN 2176-9575 
Ao analisar a cultura da subalternidade versus o protagonismo popular na política de assistência social, Yasbek (2014) define a experiência trágica de pertencer às classes subalternas, isto é,

[...] fazer parte de um universo caracterizado por trajetórias de exploração, pobreza, opressão e resistência, além de ser marcada por outros códigos que sinalizam a condição subalterna: o desconforto da moradia precária e insalubre; as estratégias de sobrevivência perante o desemprego; o convívio com o ilícito; a debilidade da saúde; a ignorância; fadiga; resignação; crença na felicidade das gerações futuras (YASBEK, 2014, p. 373-374).

A relação do/a Assistente Social com os indivíduos que buscam o seu trabalho deve primar pela aliança das competências teórico-metodológicas e técnico-operativas do trabalho profissional com os compromissos explicitados pelo Código de Ética Profissional. Esse compromisso é parametrizado não apenas por elementos normativos (Lei que Regulamenta a Profissão, Código de Ética e Diretrizes Curriculares), mas, também, é parte constituinte de uma extensa trajetória que aproximou a categoria profissional dos movimentos sociais, permitindo-lhe romper com o Serviço Social tradicional no interior do movimento histórico de redemocratização da sociedade brasileira (NETTO, 2011). O resultado foi a formulação de um Projeto Profissional que emergiu do processo de renovação do Serviço Social brasileiro. No que se refere, especificamente, à relação entre profissionais e usuários dos serviços, Netto (1999) afirma que esse projeto

[...] prioriza uma nova relação com os usuários dos serviços oferecidos pelos assistentes sociais: é seu componente elementar o compromisso com a qualidade dos serviços prestados à população, aí incluída a publicidade dos recursos institucionais, instrumento indispensável para a sua democratização e universalização e, sobretudo, para abrir as decisões institucionais à participação dos usuários (NETTO, 199, p. 16).

Os enfrentamentos cotidianos que visam dar cabo a esse processo requerem a compreensão da história dos sem história. Segundo Martins (2000), a história é “[...] dos que vivem à margem da história oficial, da história do poder e dos poderosos, dos que mandam" (MARTINS, 2000, p. 134). Invalidar a história dos sem história significa reduzi-la a algo administrável, a capturá-la em relatórios estatísticos que contabilizem a gestão de seu sofrimento, a subsumi-la em fichas e cadastros, equiparando-a a uma peça do mobiliário institucional. Essa forma produz um reconhecimento negativo e estigmatizante que só serve para justificar o controle social sobre essas existências.

Essa captura da complexidade do real em um processo de categorização pragmática da vida dos sujeitos reflete o que Lefèbvre (1991) considera uma espécie de estruturação e estratificação da vida cotidiana na sociedade capitalista moderna. O efeito disso é o real não se constituindo em um processo dialético complexo, mas como algo meramente pronto e dado, decifrável por meio de processos burocráticos de preenchimento de documentos e encaminhamentos técnicos. No interior do exercício profissional, todavia, isso dificulta a reflexão crítica sobre o significado do que faz o/a Assistente Social ao ser obliterada a perspectiva crítica, passando a adotar os preceitos e indicativos meramente burocráticos na relação com o outro. 
Incorrer em uma relação acrítica com os usuários do trabalho profissional leva à coleta de suas informações como mero recurso instrumentalizador para racionalizar os recursos institucionais, possibilitar a exclusão e permitir o corte de direitos.

Ainda sobre isso, Martins (2000) alerta sobre os riscos da generalização dessa população, isto é,

[...] no geral o marxismo errou ao fetichizar as categorias de operário e camponês e ao considerá-las categorias fixas, imutáveis. A designação 'operário' permanece a mesma há mais de cem anos, mas o operário não é mais o mesmo nem é o mesmo em todos os lugares. O mesmo ocorre com o camponês. É curioso que os marxistas não tenham prestado atenção à razoável diversidade da concepção de 'camponês' em diferentes obras de Marx (MARTINS, 2000, p. 168).

Ora, se por um lado reconhecer a condição enquanto classe trabalhadora dos indivíduos atendidos é determinante para o entendimento da realidade, por outro trivializar essa condição na medida em que se desconsidera ou se ignora a materialidade singular que essas existências apresentam, também, se torna outra forma - ainda que diferente - de reforçar a negação desses sujeitos.

O exercício do/a profissional de Serviço Social, em qualquer espaço sócio-ocupacional, pressupõe

[...] compreender a realidade no seu movimento, captar nela possibilidades de ação, priorizar, planejar, executar e avaliar, num movimento permanente contínuo e conjunto [...]. Prevê, ainda, a articulação com outros profissionais, a adoção de uma postura política favorável aos usuários, e o estabelecimento de redes para configurar uma força social em busca de uma sociedade justa e igualitária (VASCONCELOS, 2003, p. 416).

A essa reflexão pode-se acrescentar que a eficácia do conhecimento dessa realidade para a produção de estratégias do exercício profissional passa pelo reconhecimento dos indivíduos que são atendidos como sujeitos que - na forma como contam a sua realidade - possuem uma história e podem narrá-la. Nesses termos, identificar e conhecer o objeto da intervenção profissional passa pelo conhecimento não apenas da forma como ele se manifesta ou é recortado no atendimento institucional, mas, principalmente, pela forma como os sujeitos o materializam em suas falas, em suas recusas, em sua rejeição ao que lhe é imposto, na reivindicação do que entende ser necessário.

O que importa na relação com os usuários do Serviço Social é constituir a partir deles e com eles espaços de protagonismo. Pode-se afirmar que essa condição é necessária para que o/a Assistente Social não seja um mero profissional a serviço da racionalização estatal da vida dos pobres.

No âmbito da Supervisão Acadêmica de Estágio isso pode ser fomentado, inicialmente, pela estrutura das ementas e dos programas de Supervisão de Estágio em busca do

Argum., Vitória, v. 12, n. 3, p. 296-307, set./dez. 2020. | ISSN 2176-9575 
reconhecimento do território ou das demandas dos sujeitos atendidos, cujos processos organizativos foram atravessados pela história dos sem história.

Não é suficiente, todavia, centrar as atenções somente nas ementas das disciplinas de Estágio. O Estágio em Serviço Social no processo de formação e trabalho profissional apresenta exigências que implicam reconhecer a necessidade de referências acerca de temas transversais às expressões da questão social, bem como o aprendizado da centralidade que os processos políticos organizativos reivindicatórios ocupam na formulação de direitos. Assim, "[...] os direitos têm sempre sua primeira expressão na forma de expectativa de direito, ou seja, de demandas que são formuladas, em dado momento histórico determinado, por classes ou grupos sociais" (COUTINHO, 2008, p. 53).

Ao não propiciar estratégias político-organizativas a quem se destinam os serviços, tem-se efeitos deletérios na medida em que o profissional do Serviço Social se afasta dos movimentos da sociedade civil, reproduzindo uma concepção que atesta que os direitos nascem do Estado e não do conflito das lutas sociais. No âmbito da Supervisão de Estágio isso pode resultar numa apreensão despolitizada por parte do estagiário, que não teria meios para praticar o aprendizado profissional no espaço constituído entre movimentos sociais, políticas públicas e expressões da questão social.

\section{Considerações finais}

A burocratização e a cadastrização dos indivíduos atendidos, ao serem convertidas em fichas de arquivos, indicam o que é preciso evitar no âmbito profissional e a sua relação com a Supervisão de Estágio. Sem uma relação ético-política atenta às histórias que atravessam os espaços sócio-ocupacionais, a tendência é pulverizar e banalizar os meios necessários ao entendimento sobre o conhecimento desses sujeitos. Ao refletir sobre o Estágio e a formação profissional, importa permitir que o estudante entenda os meios que permitem transbordar, para além do normativo ou de explicações generalistas, o conhecimento acerca da população atendida.

Ao mesmo tempo, é necessário que o estágio em Serviço Social - enquanto campo de aprendizado - se constitua no reconhecimento da sua complexidade, isto é, nele está em jogo a cultura organizativa, o funcionamento interno das necessidades institucionais e suas alianças táticas. Faz-se necessário, assim, que as atividades administrativas e burocráticas sirvam para apreender o processo do percurso - muitas vezes excludente - que o demandante dos serviços sociais realiza e que pode ser auxiliado pelo profissional, de modo a evitar a trajetória vacilante, sofrida pelos sujeitos, entre os serviços, políticas e espaços sócio-ocupacionais.

O conhecimento institucional é condição ineliminável para a aliança com os sujeitos do trabalho profissional. Nessa perspectiva, a questão é pensar sobre o tipo de inserção e atividade que o estagiário vai proceder para reconhecer o exercício de uma autonomia que, sob a supervisão profissional, sugere potencialidades e sua identificação com a profissão. É comum, para isso, pensar o projeto de intervenção

Argum., Vitória, v. 12, n. 3, p. 296-307, set./dez. 2020. | ISSN 2176-9575 
como um momento para essa ação, nele é possível privilegiar, também, o reconhecimento da população como um dos eixos centrais do exercício de estágio.

As demandas apresentadas pelos sujeitos podem constituir a angulação que permite, inclusive, melhor entendimento das disposições das normas e da compreensão do espaço institucional como um lugar de partida que articula a capacidade heurística e a tomada de posição política aliada ao projeto ético-político profissional. Conhecer, segundo Marx, requisita que se parta da realidade e, no processo de constituição do pensamento, se entenda que há uma ligação inseparável entre o agir e o conhecer. A leitura dos acontecimentos e o entendimento de suas relações não são abstrações aleatórias e assépticas, mas derivam da trama sociopolítica na qual os indivíduos estão situados. No exercício profissional o convite e, principalmente, o aceite torna os/as Assistentes Sociais protagonistas que se unem ao processo formativo como uma estratégia político-organizativa da categoria profissional, assegurando a efetivação do estágio como requisitada pela categoria profissional no processo de formação.

Para isso, o aprendizado da escuta é exercício fino - a despeito da escuta qualificada pelo ouvido institucional - para o reconhecimento dessa história, desde as demandas dos sujeitos atendidos, seus processos organizativos e aprendizados. Recolher os fragmentos da literatura oral do passado é um processo cujo registro é atravessado pela história dos sem história, constituindo-se em uma modalidade de prática que se coloca ao lado da população atendida pelo/a Assistente Social, de modo a construir estratégias profissionais que partam da realidade daqueles sujeitos sem, contudo, subsumi-los no processo.

O que importa na relação com o usuário do Serviço Social é, permanentemente, a análise das condições de sua subalternização e a busca por não reiterá-las nos atendimentos institucionais organizados pelas políticas sociais, mas, sim, constituir a partir dele e com ele espaços de protagonismo. Para isso, torna-se necessário superar o estranhamento que se tem em relação "[...] à sua cultura, linguagem, ao seu saber do mundo e sofrimento” (YASBEK, 2014, p. 377). Pode-se afirmar, por derradeiro, que essa condição é necessária para que o/a Assistente Social não seja mais um profissional a serviço da racionalização estatal da vida dos pobres, mas, sim, um aliado político da população com quem trabalha. $\mathrm{O}$ estágio, certamente, pode constituir-se estratégico na construção desse aprendizado.

\section{Referências}

ASSOCIAÇÃO BRASILEIRA DE ENSINO E PESQUISA EM SERVIÇO SOCIAL; CENTRO DE DOCUMENTAÇÃO E PESQUISA EM POLÍTICAS SOCIAIS E SERVIÇO SOCIAL. Diretrizes Gerais para o Curso de Serviço Social - Com base no Currículo Mínimo aprovado em Assembleia Geral Extraordinária de 8 de novembro de 1996. Rio de Janeiro, nov. 1996a. Disponível em: http://www.abepss.org.br/briefing/documentos/Lei_de_Diretrizes_Curriculares_1996. pdf. Acesso em: 10 set. 2020. 
ABESS/CEDEPSS. Associação Brasileira de Escolas de Serviço Social/Centro de Documentação e Pesquisa em Políticas Sociais e Serviço Social. Formação profissional: trajetórias e desafios. Caderno ABESS, São Paulo: Cortez, Caderno Especial, n. 7, $1996 b$.

ABREU, Mariana Maciel. Diretrizes Curriculares do curso de Serviço Social: sobre o processo de implementação. Temporalis, Brasília (DF): Associação Brasileira de Ensino, Pesquisa em Serviço Social, ano 7, n. 14, jul./dez. 2007.

BRASIL. Ministério da Educação e Cultura.Conselho Nacional de Educação. Resolução n. 15, de 13 de março de 2oo2. Diretrizes Curriculares para os Cursos de Serviço Social. Brasília (DF), 2002. Disponível em:

http://www.abepss.org.br/briefing/documentos/legislacao_diretrizes_cursos.pdf.

Acesso em: 21 set. 2020.

CONSELHO FEDERAL DE SERVIÇO SOCIAL. Legislação e Resoluções sobre o Trabalho do Assistente Social. Lei de Regulamentação da Profissão (Lei n. 8.662/2003). Brasília (DF), 2011a. Disponível em: www.cfess.org.br. Acesso em: 4 ago. 2020 .

CONSELHO FEDERAL DE SERVIÇO SOCIAL. Legislação e Resoluções sobre o Trabalho do Assistente Social. Código de Ética do Assistente Social. Brasília: CFESS, 2011b. Disponível em: www.cfess.org.br. Acesso em: 4 ago. 2020.

CONSELHO FEDERAL DE SERVIÇO SOCIAL. Legislação e Resoluções sobre o Trabalho do Assistente Social. Resolução CFESS 533/2008. Regulamenta a Supervisão Direta de Estágio no Serviço Social. Brasília: CFESS, 2011c. Disponível em: www.cfess.org.br. Acesso em: 4 ago. 2020.

CONSELHO FEDERAL DE SERVIÇO SOCIAL; CONSELHO REGIONAL DE SERVIÇO SOCIAL. Sou Assistente Social e Supervisiono Estágio: a supervisão qualifica a formação e o trabalho. Brasília (DF), 2017. Disponível em: http://www.abepss.org.br/arquivos/anexos/supervisao_estagio_2017_ panfleto_a4_3_alt-201801291758231134350.pdf. Acesso em: 10 jun. 2019.

COUTINHO, Carlos Nelson. Contra a corrente: ensaios sobre democracia e socialismo. 2. ed. São Paulo: Cortez, 2008.

IAMAMOTO, Marilda Villela Iamamoto. Projeto profissional, espaços ocupacionais e trabalho do (a) assistente social na atualidade. Atribuições privativas do assistente social em questão. Brasília (DF): Conselho Federal de Serviço Social, 2012.

IAMAMOTO, Marilda Villela. O serviço social na contemporaneidade: trabalho e formação profissional. 3. ed. São Paulo: Cortez, 2003. 
JESUS, Maria Carolina de. Quarto de despejo: diário de uma favelada. 10. ed. São Paulo: Ática, 2018.

LEFÈBVRE, Henri. A vida cotidiana no mundo moderno. São Paulo: Ática, 1991.

MARTINS, José de Souza. A sociabilidade do homem simples. São Paulo: Hucitec, 2000.

NETTO, José Paulo. Ditadura e Serviço Social: uma análise do Serviço Social no Brasil pós-64. 16. ed. São Paulo: Cortez, 2011.

NETTO, José Paulo. A construção do projeto ético-político do Serviço Social. In:

MOTA, Ana Elizabete. Serviço Social e Saúde: formação e trabalho profissional. São Paulo: Cortez, 1999. Disponível em: http://www.ssrede.pro.br/wpcontent/uploads/2017/o7/projeto_etico_politico-j-p-netto_.pdf. Acesso em: 10 jun. 2019 .

VASCONCELOS, Ana Maria de. A prática do serviço social: cotidiana formação e alternativas na área da saúde. São Paulo: Cortez, 2003.

YASBEK, Maria Carmelita. Cultura da Subalternidade e o protagonismo popular na política de assistência social: uma equação possível. In: PAIVA, Beatriz Augusto (Org.). Sistema Único de Assistência Social em perspectiva: direitos, política pública e superexploração. São Paulo: Veras, 2014.

Simone Sobral Sampaio Trabalhou na concepção e delineamento, análise e interpretação dos dados. Graduação em Serviço Social pela Pontifícia Universidade Católica de Goiás (1990). Mestrado em Filosofia pela Universidade Federal de Goiás (1998). Doutorado em Serviço Social pela Universidade Federal do Rio de Janeiro (2003). Pós-Doutorado (2011,CAPES), na Université Paris XII, em colaboração com Frédéric Gros e Pós-Doutorado (2017,CAPES), na Université Paris X, em colaboração com Judith Revel.

Robson de Oliveira Trabalhou na concepção e delineamento, análise e interpretação dos dados.

Graduação em Serviço Social pela Universidade Federal de Santa Catarina (2010). Mestrado em Serviço Social pela Universidade Federal de Santa Catarina (2014). Doutorado em Serviço Social pela Universidade Federal de Santa Catarina (2019). Atuou como Assistente Social em um presídio na cidade de Itajaí (Canhanduba, 2011) e na Prefeitura Municipal de São José (2013-2014) no CRAS - Colônia Santana e como Coordenador do Centro de Referência Especializado para População em Situação de Rua.

Argum., Vitória, v. 12, n. 3, p. 296-307, set./dez. 2020. | ISSN 2176-9575 